DOI: 10.19195/0137-1150.169.6

Data przesłania artykułu: 27.03.2018

Data akceptacji artykułu: 10.11.2018

\title{
ANDREY ZAYNULDINOV
}

Universitat de Barcelona, Hiszpania

\section{Синтагматические особенности функционирования русских экспрессивных языковых единиц (на материале лексики с положительной эмоциональной оценкой)}

Актуальность исследований, посвященных функционированию экспрессивной лексики, объясняется активно формирующимися в настоящее время категориями лингвокультурологии, в рамках которой прагмалингвистический подход ${ }^{1}$ позволяет уточнить некоторые семантические закономерности, связанные с экспрессивностью и эмотивной оценочностью.

Специфика прагматического (в отличие от дескриптивного) значения определяет особую роль синтагматики; вероятно, можно даже говорить о закономерностях использования эмоционально-оценочной лексики с определенными прагматическими целями. Справедливо утверждение Нины Арутюновой о том, что „прагматическое значение раскрывается через синтаксис. Различие в синтаксических позициях, занимаемых оценочными предикатами, в свою очередь связано с различиями в природе тех объектов, которые они определяют"2. Исходя из противопоставления функции идентификации и функции предикации, целесообразно рассмотреть синтагматические особенности употребления лексики с положительной эмо-

* Данная работа осуществлена в рамках проекта „SOMEMBED-SLANG: Comprension del Lenguaje en los medios de comunicacion social Испанского министерства экономики и развития".

1 Л. А. Киселева, Вопросы теории речевого воздействия, Ленинград 1978.

${ }^{2}$ Н. Д. Арутюнова, Типы языковых значений. Оиенка. Событие. Факт, Москва 1998, c. 7 . 
циональной оценкой в наиболее типичных для них позициях обращения и предиката.

В результате анализа языкового материала сделан вывод о различии типологии лексических единиц, выражающих одобрение и восхищение, которые в позиции обращения не претерпевают семантических изменений (для данных слов позиция обращения не является системной, определяющей): орёл, соловей, мастер, и типологии лексических единиц, выражающих ласковое и дружелюбное отношение, которые в позиции обращения выражают собственно-оценочную семантику при деактуализации номинативных компонентов значения (позиция обращения является системной, основополагающей: лапушка, ягодка, сынок, дружище и т. п.).

Собственно-оценочная семантика может быть определена общими компонентами значения 'милый, дорогой' большей степени интимизации для выражения ласкового отношения в компонентах значения 'дорогой, дружище' меньшей степени интимизации для выражения дружелюбного отношения.

Лексемы (ЛСВ слов), выражающие ласковое и дружелюбное отношение, чаще всего употребляются в обращениях одиночно, без определений: „Книга, дружище, как хороший сад, где всё есть, и приятное, и полезное” (М. Горький, В людя $x$ ); ,_- Что так рано поднялся, касатик? - дружелюбно, как к старому доброму знакомому, обратилась к нему старуха-хозяйка" (Л. Толстой, Анна Каренина); „- Дядя! Голубчик! Позвольте мне теперь уехать!" (М. Салтыков-Щедрин, Господа Головлевы), часто в восклицательных предложениях.

При использовании вторичных оценочных значений лексических единиц ТГ наименований лиц по родственным связям актуализаторами оценочной семантики являются слова, определяющие неродственные отношения между участниками речевого акта, вычленяемые из узкого или расширенного контекста: „Воды нагреть вам? - деловито спросила хозяйка. — Чай у нас есть, тётушка. И вас угостим" (А. Лебеденко, Тяжёльй дивизион); „Работали вы споро, честно; надо, чтобы я вам спасибо сказал; вот я и говорю: спасибо, братцы!” (М. Горький, Старик); „- Эй, ты куда, мамаша. - А туда ж, - домой, сынок” (А. Твардовский, Василий Тёркин).

При использовании в качестве определителей к лексемам с положительной эмоциональной оценкой других прилагательных отмечается особенность, заключающаяся в отнесении семантики прилагательных к адресату оценки вне соответствия с денотативным содержанием оценочной номинации: „Подруга дней моих суровых, голубка дряхлая моя!” (А. Пушкин, Няне); ,- Матушка, кровинушка ты моя", - говорит (стал он тогда такие любезные слова говорить, неожиданные), кровинушка ты моя милая, радостная" (Ф. Достоевский, Братья Карамазовы).

Дескриптивные слова, не обладающие квалификативным смыслом, не используются в предикативных позициях, что позволяет признать роль пре- 
дикативных позиций как дифференциаторов дескриптивных и оценочных смыслов, актуализаторов и сенсибилизаторов признаковых сем, противопоставленных аналогичным по форме позициям идентификации и классификации (ср. Он - дипломат (профессия); Это - коза (животное)) $)^{3}$.

Прежде всего следует отметить реализацию собственно-оценочной семантики лексемами, относящимися к уровню восхищения, в синтаксической позиции предиката: структурной схеме предложения N1 - NN1: „(Огнева) Ваш город - игрушка, прелесть” (А. Н. Толстой, Кукушкины слезы), часто в восклицательных предложениях: „(Гак:) За ваше здоровье, Сергей Антипыч. Мадера - шик! (Мелкин:) Замечательная мадера!” (Б. Ромашов, Воздушный пирог); „(Андрей:) Ты сегодня - шик, блеск, нарядная!” (В. Розов, В добрый путь) (значительно реже определяемое слово находится в постпозиции к оценочной лексеме); структурной схеме предложения NN1 (экспрессивно-значимые односоставные предложения): „(Анна Андреевна:) - Ax, какой приятный (гость). (Марья Антоновна:) Ах! Милашка!” (Н. Гоголь, Ревизор); „Когда она от нас отошла, я шепнул Григорию Александровичу: - Ну что, какова? - Прелесть! - отвечал он” (М. Лермонтов, Бэла); „(Наркис:) Мне житьё теперь... мне житьё! Малина! Умирать не надо” (А. Островский, Горячее сердие).

Собственно-оценочные единицы, выражающие восхищение, способны выступать в позиции предиката в восклицательных предложениях других структурных схем: „Как она пляшет! Как поёт! А вышивает золотом - чудо! Не бывало такой жены и у турецкого падишаха" (М. Лермонтов, Бэла); „(Юлинька:) - А мы вчера в парке были. Как весело было - чудо!” (А. Островский, Доходное место), в невосклицательных предложениях: „Люди они добрейшие, сестре у них будет - лафа” (И. Тургенев, Новь) (не только имена существительные: „Грандиозно! Прекрасно чувствовал себя всю дорогу!” (В. Шукшин, Верую)), также чаще всего в самом конце высказывания.

Наиболее обусловлены позицией предиката лексемы с положительной эмоциональной оценкой, выражающие одобрение и восхищение, которые относятся к лексическим единицам с ,функционально-синтаксически ограниченным значением" ${ }^{\text {. }}$ К таким единицам относятся лексемы и ЛСВ слов, квалифицирующие лиц: молодещ: „Он даже радовался, говорил, что она молодец, что приехала” (Ю. Трифонов, Другая жизнь); молодчага („Арапчонок два раза перевернулся в воздухе, стал на ноги и сделал публике ручкой. - Браво! ... Молодчага!" (А. Серафимович, Полосатьй зверь); умниия („А родная дочь что ни сделай - за всё погладят по головке: умница” (А. Н. Толстой, Морозко); оценивающие предмет, лицо или ситуацию: блеск,

${ }^{3}$ Е. М. Вольф, Функциональная семантика оценки, Москва 1985, с. 31.

${ }^{4}$ В. В. Виноградов, Основные типы лексического значения слова, [в:] idem, Избранные труды. Лексикология и лексикография, Москва 1977, с. 184. 
шик, красота, чудо, прелесть; „- Отремонтируйте её - это же чудо!” (В. Шукшин, Мастер); ,- - Смотри, денёк-то какой выдался! Солнце, речка, кувшинки вон плавают... Красота, да и только” (М. Шолохов, Они сражались за Родину); „Поди выбери Денисова. Вот танцует! Чудо! - сказал он” (Л. Толстой, Война и мир).

Рассмотренные выше единицы представляют собой лексемы (ЛСВ слов) с собственно-оценочной семантикой и могут оценивать предмет оценки по чрезвычайно широкому ряду положительно оцениваемых признаков, ограниченному при характеристике лиц сферой деятельности, поведения.

Также только в позиции предиката функционируют некоторые лексемы с номинативно-оценочной семантикой: ,- Я никому никогда не рассказывал. Конечно, Ивана исключая... Но Иван - могила” (Ф. Достоевский, Братья Карамазовы); ,- - Что за пироги, если б вы только знали: сахар, совершенный сахар!” (Н. Гоголь, Вечера на хуторе близ Диканьки), „Но всего лучше... рыжики солёные, ежели их изрезать мелко, как икру, и, понимаете ли, с луком, с прованским маслом ... объедение!” (А. Чехов, Сирена).

При этом часть номинативно-оценочных единиц развивает собственно-оценочное значение, может определять предмет оценки по значительному числу признаков: „А какая у меня, братцы, в городе баба осталась, - caxap!” (А. Куприн, Поход) (признак привлекательности, характерный для вторичных наименований лиц лексемами ЛТГ 'сладости’), „Статья Герцена - прелесть, объедение. Давно уже я не читал ничего, что бы так восхитило меня” (В. Белинский, Письма), „- Посмотрите, какой прекрасный рабочий ящик, просто объедение, и настоящей французской работы” (Д. Григорович, Лотерейный бал), „- Ты хозяин, твоя и цена! ...Я-я: Ну, так по моим ценам и за пятьдесят рублей не купите... у меня конь-то изюмина!” (Н. Наумов, Погорельцы), „Как он хорош, а конь — картина!” (М. Лермонтов, Тамбовская казначейша) (признаки высокого качества: содержания статьи, работы, достоинств лошади).

Собственно-оценочный характер семантики может определяться также в связи с диффузностью значения лексем: „Какой у вас этот прелестный мальчик! - прибавила она, любуясь Мишанкой, - просто загляденье!" (М. Салтыков-Щедрин, Пошехонская старина) (то, на что можно заглядеться).

Следует отметить, что позиция предиката обусловливает также актуализацию положительной эмоциональной семантики лексем, обозначающих не оценочные понятия, которые могут выступать в качестве предмета оценки. Актуализируемый признак 'настоящий, истинный, такой, который соответствует лучшим образцам’ реализуется при употреблении в позиции предиката ЛСВ слов вещь — 'нечто ценное, значительное, прекрасное': Beщьь! Bom, это вещьь! (о спектакле, книге и т. п.), личность, индивидуальность, человек, интеллигент, мужчина („Филя так и сказал на правлении колхоза. - Саня - это человек. Отвяжитесь от него" (В. Шукшин, За- 
лётный)). Данные лексемы не могут быть отнесены к числу номинаций с языковой (узуальной) положительной оценкой, тем не менее указанная закономерность системна и регулярна. Значение указанных единиц в предикативных позициях идентично значению словосочетаний настоящзий, истинныц̆, лучший (человек, вещзь, мужчина).

Общей характеристикой подобных лексических единиц является обозначение в первичных значениях родовых понятий, возможность участвовать в конструкциях предикативных позиций: мужчина, а не тряпка; личность, а не винтик; вещьь, а не ерунда, в конструкциях сенсибилизации: Вот мужчина так мужчина! Что за вещь эта книга!

В позиции предиката используются также лексемы с конструктивно обусловленным значением ${ }^{5}$, реализующие оценочную семантику в определенных грамматических конструкциях.

К типичным конструкциям, актуализирующим положительную оценочность лексических единиц с собственно-оценочным значением, относятся:

a) существительное + чего или какой (какая);

б) существительное + в чем, на что, чем;

в) существительное + инфинитив.

Наиболее частотно использование лексем, оценивающих лицо: „Адъютант-распорядитель, мастер своего дела, крепко обняв свою даму, пустился с нею” (Л. Толстой, Война и мир); „Молодой малый, широкоплечий богатырь, работник взялся проводить [Нехлюдова]" (Л. Толстой, Воскресение); ,- Один молодой корнет, цвет и надежда высшего семейства, глядя на него, усмехнулся" (Ф. Достоевский, Хозяйка), гораздо реже в позиции приложения употребляются единицы, оценивающие предмет: „Пред ним ростбиф окровавленный, и трюфли, роскошь юных лет, французской кухни лучший цвет” (А. Пушкин, Евгений Онегин).

К особенностям употребления эмоционально-оценочной лексики следует отнести регулярное распространение оценочных единиц притяжательными и указательными местоимениями, выполняющими функцию актуализации семантики положительной эмоциональной оценки за счет соотнесения с адресатом (предметом) оценки: „Берегите наш язык, наш прекрасный русский язык, этот клад, это достояние, переданное нам нашими предшественниками” (И. Тургенев, По поводу Отціов и детей); „(Анучкин:) А как, позвольте узнать, Сицилия... (Жевакин:) А прекрасная!.. Этакие горы, и везде итальяночки, такие розанчики, так вот и хочется поцеловать” (Н. Гоголь, Женитьба) (указательные местоимения такой, этот); „Троекуров отдал полную справедливость винам своего амфитриона и искусству его повара” (А. Пушкин, Дубровский); „(Графиня) ничего не хотела слышать об отъезде до тех пор, пока не вернется её сокровище, обожаемый Петя” (Л. Толстой, Война и мир) (притяжательные местоимения свой, его, её).

${ }^{5}$ Ibidem, c. 187. 
Необходимо отметить, что рассмотренные местоимения способны не только актуализировать оценочную семантику (свой амфитрион, этот клад), соотнося оценочную единицу с адресатом (предметом) оценки, но и выступать в роли сенсибилизаторов (усилителей) выражения положительной эмоциональной оценки: указательные местоимения так, такой, такие.

Как отмечалось выше, непредикативные синтаксические позиции не характерны для функционирования лексики с положительной эмоциональной оценкой, данная лексика (прежде всего существительные) не могут выступать в конструкциях 'первого представления'

Интересны случаи сочетания наречий с прилагательными и глаголами, в первом случае реализуется семантика интенсивности, во втором случае оценочная семантика: идеально - '2. нареч. также в знач. сказ. (в сочетании с глаголом), (разг.) восх. В совершенстве, превосходно. ср. 1. (в сочетании с прилаг.), в высшей степени, совсем’” „(Крюков) играл идеально в винт” (А. Чехов, Тина); изумительно.

Значительное место среди лексических единиц, употребляющихся в позиции предиката, занимают лексемы, используемые в конструкции так называемой 'ложной классификации', строящейся на прямой таксономической оппозиции. Данная конструкция относится к ряду связанных и представляет собой усложненную конструкцию с выражением сопоставительнопротивительных отношений, обусловленных наличием таких формальных элементов, как противительный союз $a$ и частица не. Указанная конструкция с утвердительно-отрицательным значением выражает экспрессивную качественную характеристику через отрицание предикативного признака с номинативным значением.

При использовании в рассматриваемой конструкции лексем с положительной эмоциональной оценкой усиливается эффект воздействия. Наиболее частотна позиция существительного с оценочной семантикой в постпозиции по отношению к определяемому слову (существительному) с номинативной семантикой, в роли которого выступают обозначения лиц либо предметов: „(Лидия:) Ай! Я упаду в обморок. Это не коляска, а мечта. Можно задохнуться от счастья сидеть в такой коляске" (А. Островский, Бешеные деньги), „Видный такой пастырь, осанистый, бородатый - не архиерей, а конфетка!” (А. Куприн, С улищь).

Среди обозначений неконкретных предметов в качестве предмета оценки частотно реализуются лексемы жизнь, житьё: „Не жизнь, а мармелад. Все жалостно на тебя смотрят, везде, куда не придешь, закуска и выпивка, все деньги дают” (А. Чехов, В Париж); „Что ему, Ермолаю-то Евгеньичу, не житьё, а масленица" (Д. Мамин-Сибиряк, На месте преступления).

${ }^{6}$ Ibidem, c. 156. 
Оценочные номинации могут использоваться и в препозиции по отношению к определяемому слову: „Я этого Володю Осьмухина прекрасно знаю - золото, а не парень” (А. Фадеев, Молодая гвардия).

Положительная эмоциональная оценка актуализируется смыслом высказывания в целом, другими лексическими единицами: „Очень часто из старого перекрашенного платья, из ничего не стоящих кусочков тюля, кружев, плюша и шёлка выходят просто чудеса, нечто обворожительное, не платье, а мечта” (А. Чехов, Попрыгунья); „Дело прошлое и скромничать нечего, а потому скажу вам, что мост получился у меня великолепный! Не мост, а картина, один восторг!” (А. Чехов, Пассажир 1 класса); „Ты дома сама себе госпожа, - кого хочешь, того любишь. Эх, не жизнь, а масленица!” (А. Чехов, Бабье ичарство); „-ХХрактер у него особенный: грубого слова не слыхивали, обиды не знали. Шёлк, а не парень” (Д. Мамин-Сибиряк, $B$ худых душах).

Безусловно, предложенный анализ не является исчерпывающим исследованием синтагматического аспекта функционирования эмоциональнооценочной лексики, но тем не менее выявленные семантические закономерности могут быть использованы при развитии концепций лингвокультурологии и стилистики, а также в лексикографической практике и преподавании русского языка как иностранного.

\section{Библиография}

Arutûnova N. D., Tipy âzykovyh značenij: Ocenka. Sobytie. Fakt, Moskva 1988.

Kiseleva L. A., Voprosy teorii rečevogo vozdejstviâ, Leningrad 1978.

Vinogradov V. V., Osnovnye tipy leksičeskogo značeniâ slova, [v:] idem, Izbrannye trudy. Leksikologiâ i leksikografiâ, Moskva 1977.

Vol'f E. M., Funkcional'naâ semantika ocenki, Moskva 1985.

\section{Syntagmatic features of the functioning of Russian expressive linguistic units (on the basis of a vocabulary with a positive emotional evaluation)}

Summary

Proceeding from the opposition of the function of identification and the function of predication, it is advisable to consider the syntagmatic features of the use of a vocabulary with a positive emotional evaluation in the most typical positions of vocative and predicate.

As a result of the analysis of linguistic material, a conclusion has been made about the difference in the typology of lexical units expressing approval and admiration, which do not undergo semantic changes in the vocative position (for the given words, the vocative position is not systemic, determining): орёл oriol (eagle), соловей solovej (nightingale), мастер master (master), and the typologies of lexical units conveying an affectionate and friendly attitude that in the attitude of 
the expression communicates the properly-valued semantics in the eventual deactivation of the nominative components of the value (the vocative position is systemic, basic: лапушка lapushka [little paw], ягодка jagodka [berry], сынок synok [little son], дружище druzhishe [friend, pal], etc.).

Keywords: syntagmatics, use, Russian language, vocabulary, positive emotional evaluation, expressiveness

\section{Syntagmatyczne właściwości funkcjonowania rosyjskich ekspresyjnych jednostek językowych (na materiale leksyki pozytywnie nacechowanej emocjonalnie)}

\section{Streszczenie}

Przy wychodzeniu od opozycji funkcji identyfikacji i funkcji predykacji celowe jest rozpatrzenie syntagmatycznych właściwości użycia leksyki z pozytywną oceną emocjonalną w najbardziej typowych dla nich pozycjach zwracania się i predykatu.

W wyniku analizy materiału językowego został sformułowany wniosek o rozbieżności typologii jednostek językowych wyrażających akceptację i zachwyt, które w funkcji adresatywnej nie ulegają zmianom semantycznym (dla danych wyrazów sytuacja zwrotu nie jest pozycją systemową, określającą: орел, соловей, мастер) i typologii jednostek leksykalnych wyrażających serdeczny i przyjacielski stosunek, które w pozycji adresatywnej wyrażają znaczenie wartościujące przy jednoczesnej dezaktualizacji nominatywnych komponentów znaczeniowych (pozycja zwracania się jest tu systemowa, fundamentalna: лапушка, ягодка, сынок, дружище itp.).

Słowa kluczowe: syntagmatyka, funkcjonowanie, język rosyjski, słownictwo, pozytywna ocena emocjonalna, ekspresywność 